\title{
Geo-Environmental Engineering in any Civil Construction
}

\author{
Saidur Rahman Chowdhury* \\ Assistant Professor, Department of Civil Engineering, Prince Mohammad Bin Fahd University, PO BOX 1664, Al Khobar 31952, Saudi Arabia
}

\author{
*Corresponding author: Saidur Rahman Chowdhury, Department of Civil \\ Engineering, Prince Mohammad Bin Fahd University, PO BOX 1664, Al Khobar \\ 31952, Saudi Arabia.
}

\section{Opinion}

Civil construction constitutes a significant growth of different activities in residential, industrial or commercial development. It includes the construction of high-rise multistorey buildings, hospitals, schools, industrial plants, manufacturing industries, warehouses, chemical storage buildings, garages, workshops, gas station, shopping malls, playgrounds, parklands, agricultural or mining industries etc. Because of unplanned development and lack of proper environmental management, any establishment can cause severe contamination. Thus, environment often requires site assessment, monitoring, evaluation and restoring prior to post construction period. This has resulted in an expensive environmental restoring system. Managing such pollution prevention method can cause major economic burden. Therefore, continuous investigation and research can mitigate the risk associated with the issues. Any research project pertaining to environmental restoration possesses significant impact and importance in case of construction engineering or its management.

Civil engineering covers the discipline of geo-environment, which deals with the contaminated site assessment, soil or groundwater monitoring and remediation. The solutions to environmental challenges relating to human interaction with air, water, soil and subsurface groundwater require the skill engineers who possess a broad range of knowledge and expertise. As a geoenvironmental engineer, one could be involved in a wide range of activities, including geotechnical investigation, contaminated land management, geochemical analysis, hydrogeology, water resource management, contaminant fate and transport prediction, environmental impact assessment, and environmental risk assessment. Geo-environmental is the study of approaches for solving the earth, soil and rock related any problem (for infrastructural development), soil/water interactions as well as pore water pressure investigation (for any hydraulic structure development), coastal engineering, seismic engineering, soil and ground water remediation techniques.
With the civilization as well as industrial revolution, the uses of different chemicals have been increasing. Throughout the world, soil and groundwater contamination in the big cities (e.g. Toronto, New York, Beijing and Delhi etc.) is very common and causes severe hazards to public health. To protect human health any construction site needs to be investigated prior to infrastructural development. Air, soil and groundwater should be investigated as well as assess the presence of contamination that could pose health hazard to public. The challenges can be handled by a group of engineers who has adequate knowledge about environmental investigation and remediation techniques. An unplanned development of the cities, accidental spills of toxic chemicals or careless waste disposal practices can result in subsurface contamination. The storage and the dispensing of petroleum products or leaking storage tanks at gas stations, liquid wastes from dry cleaners, oil refineries, and manufacturing plants are one of the major sources of subsurface contamination. The common carcinogenic contaminants found in the soil and groundwater are petroleum hydrocarbons (PHCs) in the fraction F1-F4, volatile organic compounds (VOCs), polycyclic aromatic hydrocarbons (PAHs), polychlorinated biphenyl (PCBs), pesticides, solvents, and metals and inorganics (M\&Is). People who live or work at or very near the contaminated site are directly at health risk. To control the risk, different regulatory agency throughout the world regulates the record of site condition (RSC) prior to any construction or redevelopment. Moreover, some part of the world, the RSC is deemed necessary when a property owner is choosing to redevelop or change the property use from a less sensitive to more-sensitive use (e.g. industrial use to residential use).

Site contamination is a complex problem that sometime naturally degrades or can persist for long period. These toxic contaminants can migrate through the soil to the groundwater and spread over a wide area. To restore the contaminated environment, scientists and engineers have been carrying out lab or field scale 
research to develop efficient, economical, environment friendly, and readily available reactive treatment technique. They also study the feasibilities of using renewable resources or recycling waste products in environmental remediation. An application of recycling of waste product for the removal of contaminants can significantly reduce the environmental footprint of industrial operations and hence contribute to sustainable development.

\section{Acknowledgment}

None.

\section{Conflict of Interest}

No conflict of interest. 